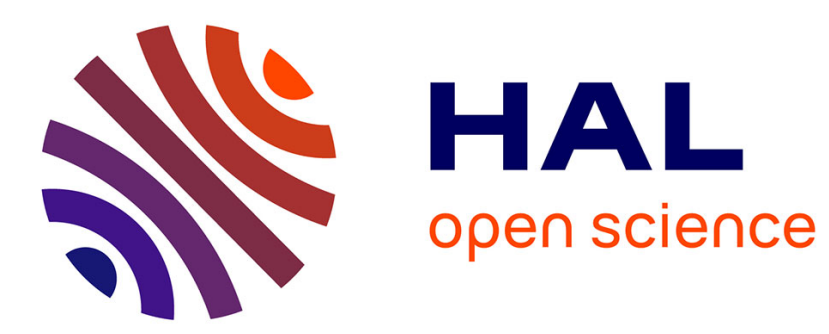

\title{
Manganese catalyzed reductive amination of aldehydes using hydrogen as a reductant
}

\author{
Duo Wei, Antoine Bruneau-Voisine, Dmitry A. Valyaev, Noël Lugan, \\ Jean-Baptiste Sortais
}

\section{- To cite this version:}

Duo Wei, Antoine Bruneau-Voisine, Dmitry A. Valyaev, Noël Lugan, Jean-Baptiste Sortais. Manganese catalyzed reductive amination of aldehydes using hydrogen as a reductant. Chemical Communications, 2018, 54 (34), pp.4302-4305. 10.1039/C8CC01787E . hal-01807069

HAL Id: hal-01807069

https://hal-univ-rennes1.archives-ouvertes.fr/hal-01807069

Submitted on 20 Jun 2018

HAL is a multi-disciplinary open access archive for the deposit and dissemination of scientific research documents, whether they are published or not. The documents may come from teaching and research institutions in France or abroad, or from public or private research centers.
L'archive ouverte pluridisciplinaire HAL, est destinée au dépôt et à la diffusion de documents scientifiques de niveau recherche, publiés ou non, émanant des établissements d'enseignement et de recherche français ou étrangers, des laboratoires publics ou privés. 


\title{
Manganese Catalyzed Reductive Amination of Aldehydes using Hydrogen as Reductant
}

\author{
Duo Wei, ${ }^{a}$ Antoine Bruneau-Voisine, ${ }^{a, b}$ Dmitry A. Valyaev, ${ }^{b}$ Noël Lugan ${ }^{b}$ and Jean-Baptiste \\ Sortais*b,c
}

\begin{abstract}
A one-pot two-steps procedure was developed for the alkylation of amines via reductive amination of aldehydes using molecular dihydrogen as reductant in the presence of manganese pyridinylphosphine complex as pre-catalyst. After the initial condensation step, the reduction of the imines formed in situ is applied under mild conditions $\left(50-100{ }^{\circ} \mathrm{C}\right)$ with 2 mol\% of catalyst and $5 \mathrm{~mol} \%$ of $t$ BuOK under 50 bar of hydrogen. Excellent yields ( $>90 \%$ ) were obtained for a large combination of aldehydes and amines (38 examples), including aliphatic aldehydes and amino-alcohols.
\end{abstract}

In the last two years, the use of manganese as a sustainable alternative to precious transition metals in hydrogenation and hydrogen borrowing reactions has achieved an impressive explosion. ${ }^{1}$ Starting from the hydrogenation of aldehydes, ketones and nitriles, ${ }^{2}$ the scope of reducible functional group was rapidly enlarged to esters, ${ }^{2 \mathrm{~d}, 3}$ amides, ${ }^{3 \mathrm{c}, 4}$ and $\mathrm{CO}_{2} \cdot{ }^{5}$ Soon after, hydrogen transfer reactions using isopropanol as reductant ${ }^{6}$ and asymmetric reduction ${ }^{2 \mathrm{~d}, 7}$ have been disclosed. In the field of hydrogen borrowing reactions, the first manganese-catalyzed dehydrogenative coupling of alcohols and amines to form imines ${ }^{8}$ was rapidly complemented by the synthesis of esters ${ }^{9}$ from alcohols, and amides ${ }^{10}$ from alcohols and amines. In the field of C-C bond formation reactions, $\alpha$ alkylation of ketones with alcohols, ${ }^{11}$ and olefination of nitriles ${ }^{12}$ were also achieved. Interestingly, the upgrading of ethanol in butanol, ${ }^{13}$ the dehydrogenation of methanol ${ }^{14}$ to $\mathrm{H}_{2}$ and $\mathrm{CO}_{2}$, or the deoxygenation of alcohols ${ }^{15}$ were also found to be catalyzed by manganese complexes. Finally, the access to various higher amine derivatives using alcohols as alkylating reagents was developed, ${ }^{16}$ including the $N$-monomethylation of amines, ${ }^{16-17}$ aminomethylation of [hetero]arenes with methanol/amines, ${ }^{18}$

a. Univ Rennes, CNRS, ISCR - UMR 6226, F-35000 Rennes, France.

b. LCC-CNRS, Université de Toulouse, CNRS, UPS, Toulouse, France

E-mail: jean-baptiste.sortais@lcc-toulouse.fr

c. Institut Universitaire de France

1 rue Descartes, F-75231 Paris Cedex 05, France

+ Footnotes relating to the title and/or authors should appear here.

Electronic Supplementary Information (ESI) available: [details of any supplementary information available should be included here]. See DOI: 10.1039/x0xx00000x and multi-component synthesis of quinolines, ${ }^{19}$ pyrroles $^{20}$ and pyrimidines. ${ }^{21}$

Reductive amination ${ }^{22}$ is one of the chemical reaction in the chemist tool-box for the preparation of amines. ${ }^{23}$ It relies on the in situ condensation of a ketone or aldehyde with an amine to form the corresponding imine, which is subsequently reduced to the desired amine. When using molecular hydrogen as reductant, it appears that the key step in the reaction sequence is the hydrogenation of the intermediate imine.

In line with our previous work on manganese catalyzed reactions ${ }^{24}$ and catalytic amines synthesis using first-row transition metals complexes, ${ }^{25}$ we report thereafter the first alkylation of amines via reductive amination of aldehydes using molecular hydrogen as reductant and well-defined manganese complexes as pre-catalysts.

We have selected complexes 1-4 as candidates for this study (Scheme 1) as we recently demonstrated that manganese (I) bromo-tricarbonyl complexes bearing bidendate pyridinylphosphine ligands were good catalysts for the hydrogenation of carbonyl derivatives, and especially complex $\mathbf{2}$ featuring diphenyl-(2-aminopyridinyl)-phosphine ligand. ${ }^{26}$

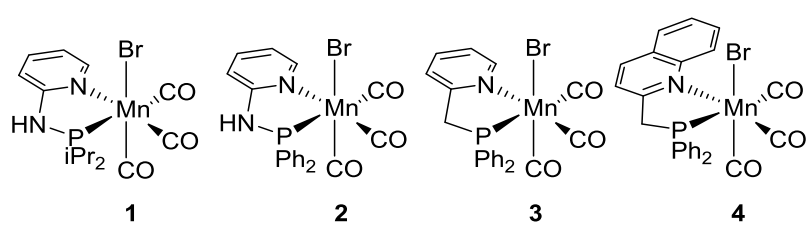

Scheme 1. Manganese complexes used in this study.

We initially focused on the direct hydrogenation of $\mathrm{N}$ benzylideneaniline $\mathbf{c} \mathbf{1}$ as model substrate, using catalyst $\mathbf{2}$ and a base, under 50 bar of $\mathrm{H}_{2}$, based on previously optimized conditions for the hydrogenation of ketones. First, we found that alcohols, and notably ethanol, were suitable solvents for the hydrogenation step (See Table S1 in S.I.) as a green solvent alternative to toluene. It then appeared that the nature of the base had little influence on the reaction, $\mathrm{NaOtBu}, \mathrm{KOtBu}$, KHMDS, or $\mathrm{Cs}_{2} \mathrm{CO}_{3}$ leading to satisfactory conversions (2 (1 
mol\%), base ( $2 \mathrm{~mol} \%$ ), $100{ }^{\circ} \mathrm{C}, \mathrm{EtOH}, 22 \mathrm{~h}, 41 \%$ to $64 \%$ yield, see Table S2 in S.I.). The activity of complexes 1-4 was compared at $80^{\circ} \mathrm{C}$ with $1 \mathrm{~mol} \%$ catalyst and $2 \mathrm{~mol} \%$ of $t$ BuOK (Table 1 , entries 1-4) and complex 2 appeared to be the most active one. Increasing the catalyst loading to $2 \mathrm{~mol} \%$ led to a full conversion (entry 5). Interestingly, the temperature could be decreased to $50{ }^{\circ} \mathrm{C}$ without any detrimental effect on activity (entry 6$)$, and even to $30{ }^{\circ} \mathrm{C}$ where a decent conversion still occurred (76\%, entry 7).

Table 1. Optimization of the reactions conditions of the hydrogenation of benzylideneaniline $\mathbf{c 1}$ with manganese catalysts 1-4.

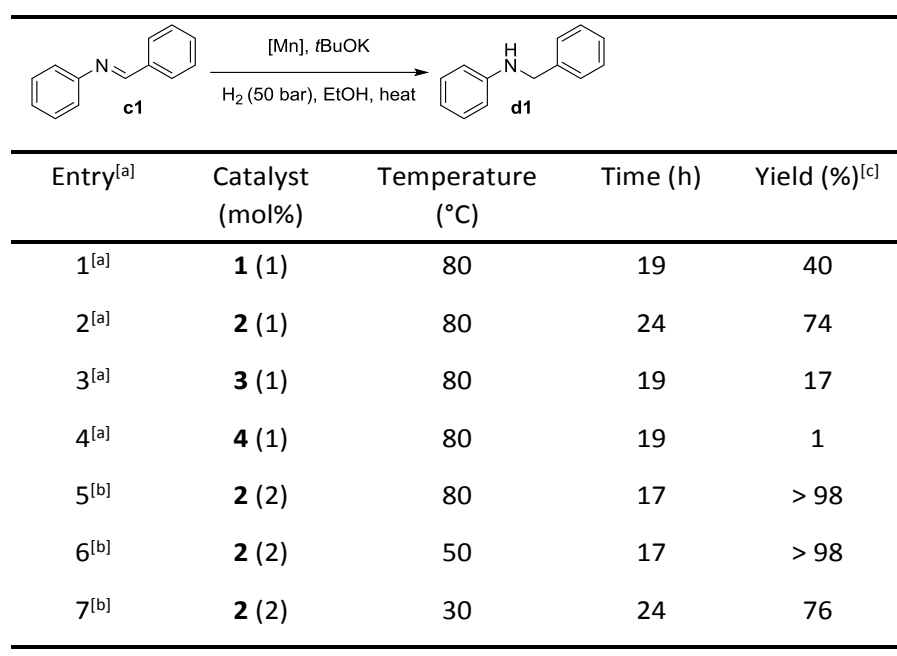

[a] Conditions: an autoclave was charged in a glovebox with, in this order, c1 (181 mg, $1.0 \mathrm{mmol}), \mathrm{EtOH}(4.0 \mathrm{~mL}), \mathrm{Mn}$-complex (1 mol\%), tBuOK (2.2 $\mathrm{mg}, 2 \mathrm{~mol} \%)$, and then pressurized with $\mathrm{H}_{2}$ (50 bar) and heated. [b] c1 (91 $\mathrm{mg}, 0.5 \mathrm{mmol}$ ), EtOH (2.0 mL), 2 (5.0 mg, 2 mol\%), tBuOK (2.8 mg, $5 \mathrm{~mol} \%$ ). [c] Yield was determined by ${ }^{1} \mathrm{H}$ NMR spectroscopy and GC on the crude mixture.

In terms of practical and economical synthesis, direct reductive amination of aldehydes is more desirable than hydrogenation of corresponding isolated imines. Hence, we turned our attention towards the direct synthesis of benzylaniline $\mathbf{d} \mathbf{1}$ from benzaldehyde a1 and aniline b1. In a first attempt, all the components, i.e. $\mathbf{2}$, a1, b1, $t \mathrm{BuOK}$, and $\mathrm{H}_{2}$, were introduced in an autoclave being heated at $80{ }^{\circ} \mathrm{C}$ overnight (Scheme 2, conditions A). Disappointingly, a mixture of benzylalcohol e1 (44\%), imine c1 (38\%), and the desired amine d1 (18\%) was obtained, showing that the hydrogenation of benzaldehyde occurred faster than the condensation with aniline. In a second strategy, the condensation step was carried out in the presence of the catalyst and the base at $80{ }^{\circ} \mathrm{C}$ for $5 \mathrm{~h}$, then the reaction mixture was pressurized under $\mathrm{H}_{2}$ and stirred at $80^{\circ} \mathrm{C}$ overnight (conditions $\mathrm{B}$ ). Unfortunately, the main products were again alcohol e1 (61\%) and imine c1 (29\%). Finally, we decided to perform first the condensation of the aldehyde with the amine in $\mathrm{EtOH}$, imine $\mathbf{c 1}$ being formed in $90 \%$ yield after $24 \mathrm{~h}$ at $100{ }^{\circ} \mathrm{C}$, and then to add the precatalyst, the base, and $\mathrm{H}_{2}$ to the crude imine before heating under stirring at $80{ }^{\circ} \mathrm{C}$ overnight (Conditions $\mathrm{C}$ ). To our delight, under these conditions, the desired $N$-benzylaniline d1 was obtained in high yield (87\%). Here after, 1.2 equivalent of amines $\mathbf{b}$ were used to ensure the full conversion of the aldehyde a into the imines $\mathbf{c}$ before the hydrogenation step (Table 2). We next probe the scope of this first manganese catalyzed reductive amination system thus defined.

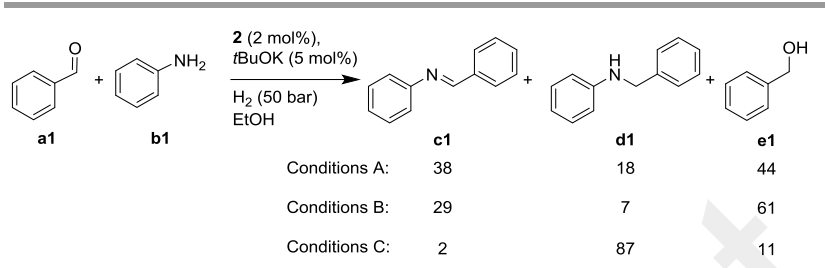

Scheme 2. Optimization of the procedure for reductive amination of benzaldehyde with aniline under the catalysis of manganese complex $\mathbf{2}$. See main text for conditions definition and SI Table S4 for experimental details.

In general, as far as the formation of the imines is not a limiting step, ${ }^{27}$ the subsequent hydrogenation proceeds well for a wide variety of aldehydes and amines (Table 2). First, benzaldehydes derivatives bearing either electron donating or electron withdrawing groups both react with anilines to afford in fine the corresponding amines in good yield (entries 1-16). Noticeably, halogen substituents (d6-d10), including iodo substituent, were well tolerated with less than $10 \%$ deiodination in the cases of d9 and d10. Esters and amides moieties were not reduced under these conditions (d12-d13). Interestingly, starting from 4formylacetophenone a14 in the presence of 2 equivalent of aniline b1, only the aldimine moieties was reduced in the transient di-imine intermediate $\mathbf{c 1 4}$ affording the corresponding amino-ketimine $\mathbf{d 1 4},{ }^{28}$ while in the presence of 1 equivalent of b1, amino-ketone $\mathbf{d} \mathbf{1 5}$ was obtained in good yield. In the same vein, the reductive amination of benzaldehyde a1 with 4-acetyl-aniline b16 led selectively to the corresponding 4-acetylamine d16 leaving the ketone functionality untouched. Organometalllic ferrocenylaldehyde a17 was also suitable for this protocol. Several heterocycles, including pyrrole, furane, pyridine, thiophene, and thiazole were well tolerated by the catalytic system (entries 18-23). It is noteworthy that this reductive amination protocol is not limited to aniline derivatives, as sulfonylamide b24 as well as aliphatic primary b25-b27 and secondary amines b28-b30 were also successfully coupled. Ethylenediamine b31 afforded the $N, N^{\prime}$ dibenzylethylenediamine d31, without formation of imidazolines. ${ }^{29}$ Remarkably, the amino-alcohols b32-b34 were alkylated to afford selectively the corresponding hydroxyamines, the pending hydroxy group not entering into a potentially competitive $\mathrm{N}$-alkylation process. ${ }^{16}$ To complete the series of amines amenable for this transformation, $\alpha$-aminoesters b35-b36 were alkylated with success. A series of aliphalic aldehydes (a37-a40), including butanal (a37), readily available by hydroformylation or bio-sourced aldehydes such cinnamaldehyde (a40), were also successfully engaged in the present reductive amination protocol. Non-conjugated $\mathrm{C}=\mathrm{C}$ were typically not reduced in the course of the reaction, while conjugated $\mathrm{C}=\mathrm{C}$ bonds were reduced under harsher conditions, ${ }^{30}$ which is in line with the selectivity observed for the reduction of $\alpha, \beta$-unsatured ketones. ${ }^{26}$ 


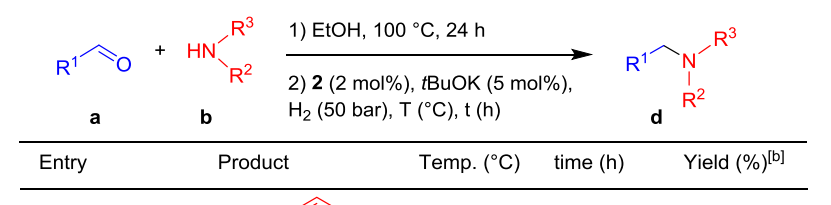

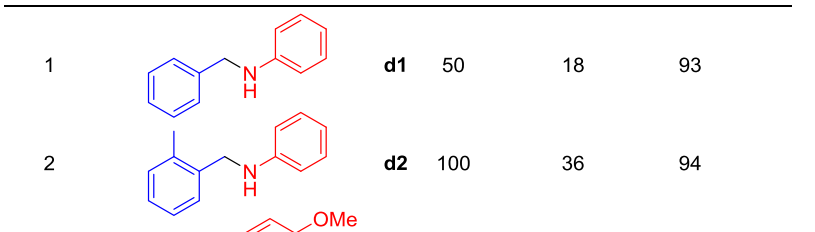

32

4

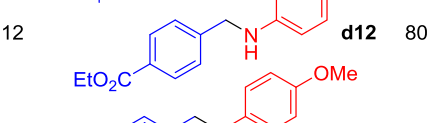
等

$14^{[\mathrm{e}]}$

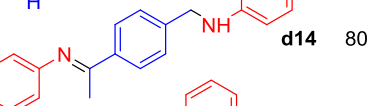

d16 50

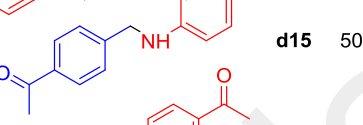

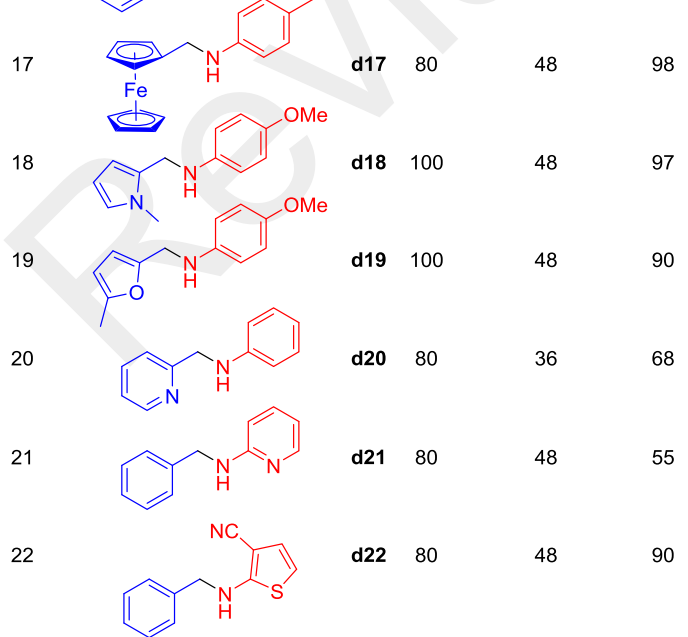

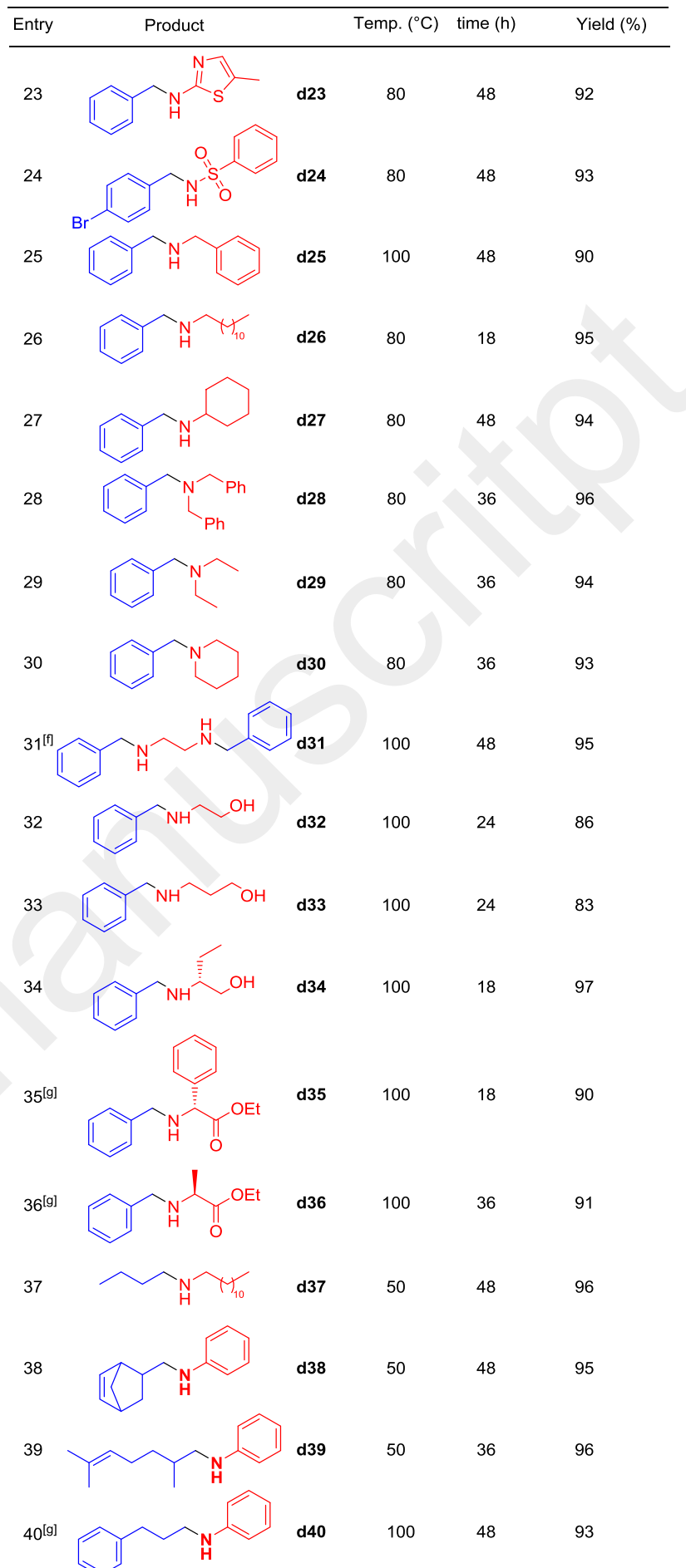

Table 2. Scope of the reductive amination of aldehydes with amines in presence of $\mathbf{2}$ as precatalyst. ${ }^{[a]}$ ([a] Typical reaction conditions: a solution of aldehyde a (0.5 $\mathrm{mmol})$, amine $\mathbf{b}(0.6 \mathrm{mmol})$ and anhydrous EtOH $(2.0 \mathrm{~mL})$ was stirred at $100{ }^{\circ} \mathrm{C}$ for $24 \mathrm{~h}$, then transferred to a $20 \mathrm{~mL}$ autoclave followed by $2(5.0 \mathrm{mg}, 2 \mathrm{~mol} \%)$ and tBuOK ( $2.8 \mathrm{mg}, 5 \mathrm{~mol} \%$ ). The autoclave was subsequently charged with $\mathrm{H}_{2}$ (50 bar) and heated. [b] Isolated yield after purification. [c] a1 (4.3 mmol), condensation: $2 \mathrm{~h}$, r.t. [d] c.a. $10 \%$ of deiodination product. [e] b1 (100 $\mu \mathrm{L}, 1.1 \mathrm{mmol})$. [f] a1 (122 $\mu \mathrm{L}, 1.2 \mathrm{mmol})$. [g] 2 (5 \% mol), tBuOK (10 mol\%).

Finally, it has to be noted that a few functional groups such as terminal alkyne, nitro group, or unprotected pyrrole were not tolerated. 
In conclusion, we have shown that a well-defined manganese pre-catalyst featuring a readily available bidendate diphenyl-(2aminopyridinyl)-phosphine ligand catalyzes efficiently the reductive amination of aldehydes using $\mathrm{H}_{2}$ as reductant with a wide functional group tolerance. This higher amines synthesis protocol significantly enlarges the scope of reactions catalyzed by manganese complexes and nicely complements a previous approach based on alkylation of amines with alcohols.

\section{Conflicts of interest}

There are no conflicts to declare.

\section{Notes and references}

1. (a) D. A. Valyaev, G. Lavigne and N. Lugan, Coord. Chem. Rev. 2016, 308, 191-235; (b) F. Kallmeier and R. Kempe, Angew. Chem. Int. Ed., 2018, 57, 46-60; (c) G. A. Filonenko, R. van Putten, E. J. M. Hensen and E. A. Pidko, Chem. Soc. Rev., 2018, 47, 1459-1483; (d) Y. Li, Y. Hu and X.-F. Wu, Chem. Soc. Rev., 2018, 47, 172-194.

2. (a) S. Elangovan, C. Topf, S. Fischer, H. Jiao, A. Spannenberg, W. Baumann, R. Ludwig, K. Junge and M. Beller, J. Am. Chem. Soc. 2016, 138, 8809-8814; (b) F. Kallmeier, T. Irrgang, T. Dietel and R. Kempe, Angew. Chem. Int. Ed., 2016, 55, 11806-11809; (c) A Bruneau-Voisine, D. Wang, T. Roisnel, C. Darcel and J.-B. Sortais, Catal. Commun., 2017, 92, 1-4; (d) M. B. Widegren, G. J. Harkness, A. M. Z. Slawin, D. B. Cordes and M. L. Clarke, Angew. Chem. Int. Ed., 2017, 56, 5825-5828.

3. (a) S. Elangovan, M. Garbe, H. Jiao, A. Spannenberg, K. Junge and M. Beller, Angew. Chem. Int. Ed., 2016, 55, 15364-15368; (b) N. A. Espinosa-Jalapa, A. Nerush, L. J. W. Shimon, G. Leitus, L. Avram, Y. Ben-David and D. Milstein, Chem. Eur. J., 2017, 23 5934-5938; (c) C. M. Kelly, R. McDonald, O. L. Sydora, M. Stradiotto and L. Turculet, Angew. Chem. Int. Ed., 2017, 56 15901-15904; (d) R. van Putten, E. A. Uslamin, M. Garbe, C. Liu, A. Gonzalez-de-Castro, M. Lutz, K. Junge, E. J. M. Hensen, M. Beller, L. Lefort and E. A. Pidko, Angew. Chem. Int. Ed., 2017, 56, 75317534.

4. V. Papa, J. R. Cabrero-Antonino, E. Alberico, A. Spanneberg, K. Junge, H. Junge and M. Beller, Chem. Sci., 2017, 8, 3576-3585.

5. (a) S. Kar, A. Goeppert, J. Kothandaraman and G. K. S. Prakash ACS Catal., 2017, 7, 6347-6351; (b) A. Dubey, L. Nencini, R. R. Fayzullin, C. Nervi and J. R. Khusnutdinova, ACS Catal., 2017, 7 3864-3868; (c) F. Bertini, M. Glatz, N. Gorgas, B. Stoger, M. Peruzzini, L. F. Veiros, K. Kirchner and L. Gonsalvi, Chem. Sci., 2017, 8, 5024-5029.

6. (a) M. Perez, S. Elangovan, A. Spannenberg, K. Junge and M. Beller, ChemSusChem, 2017, 10, 83-86; (b) A. Bruneau-Voisine, D. Wang, V. Dorcet, T. Roisnel, C. Darcel and J.-B. Sortais, Org. Lett., 2017, 19, 3656-3659.

7. (a) A. Zirakzadeh, S. R. M. M. de Aguiar, B. Stöger, M. Widhalm and K. Kirchner, ChemCatChem, 2017, 9, 1744-1748; (b) D. Wang, A. Bruneau-Voisine and J.-B. Sortais, Catal. Commun., 2018, 105 31-36; (c) M. Garbe, K. Junge, S. Walker, Z. Wei, H. Jiao, A. Spannenberg, S. Bachmann, M. Scalone and M. Beller, Angew. Chem. Int. Ed., 2017, 56, 11237-11241.

8. (a) A. Mukherjee, A. Nerush, G. Leitus, L. J. W. Shimon, Y. Ben David, N. A. Espinosa Jalapa and D. Milstein, J. Am. Chem. Soc. 2016, 138, 4298-4301; (b) M. Mastalir, M. Glatz, N. Gorgas, B. Stöger, E. Pittenauer, G. Allmaier, L. F. Veiros and K. Kirchner, Chem. Eur. J., 2016, 22, 12316-12320; (c) U. K. Das, Y. Ben-David, Y. Diskin-Posner and D. Milstein, Angew. Chem. Int. Ed., 2018 DOI: 10.1002/anie.201712593.

9. D. H. Nguyen, X. Trivelli, F. Capet, J.-F. Paul, F. Dumeignil and R. M. Gauvin, ACS Catal., 2017, 7, 2022-2032.
10. (a) S. Chakraborty, U. Gellrich, Y. Diskin-Posner, G. Leitus, L. Avram and D. Milstein, Angew. Chem. Int. Ed., 2017, 56, 42294233; (b) N. A. Espinosa-Jalapa, A. Kumar, G. Leitus, Y. DiskinPosner and D. Milstein, J. Am. Chem. Soc., 2017, 139, 1172211725; (c) A. Kumar, N. A. Espinosa-Jalapa, G. Leitus, Y. DiskinPosner, L. Avram and D. Milstein, Angew. Chem. Int. Ed., 2017, 56, 14992-14996.

11. M. Peña-López, P. Piehl, S. Elangovan, H. Neumann and M. Beller, Angew. Chem. Int. Ed., 2016, 55, 14967-14971.

12. S. Chakraborty, U. K. Das, Y. Ben-David and D. Milstein, J. Am. Chem. Soc., 2017, 139, 11710-11713.

13. S. Fu, Z. Shao, Y. Wang and Q. Liu, J. Am. Chem. Soc., 2017, 139, 11941-11948.

14. M. Andérez-Fernández, L. K. Vogt, S. Fischer, W. Zhou, H. Jiao, $M$. Garbe, S. Elangovan, K. Junge, $H$. Junge, R. Ludwig and $M$. Beller, Angew. Chem. Int. Ed., 2017, 56, 559-562.

15. J. O. Bauer, S. Chakraborty and D. Milstein, ACS Catal., 2017, 7, 4462-4466.

16. S. Elangovan, J. Neumann, J.-B. Sortais, K. Junge, C. Darcel and M. Beller, Nat. Commun., 2016, 7, 12641.

17. (a) A. Bruneau-Voisine, D. Wang, V. Dorcet, T. Roisnel, C. Darcel and J.-B. Sortais, J. Catal., 2017, 347, 57-62; (b) J. Neumann, S. Elangovan, A. Spannenberg, K. Junge and M. Beller, Chem. Eur. J., 2017, 23, 5410-5413.

18. M. Mastalir, E. Pittenauer, G. Allmaier and K. Kirchner, J. Am. Chem. Soc., 2017, 139, 8812-8815.

19. M. Mastalir, M. Glatz, E. Pittenauer, G. Allmaier and K. Kirchner, J. Am. Chem. Soc., 2016, 138, 15543-15546.

20. F. Kallmeier, B. Dudziec, T. Irrgang and R. Kempe, Angew. Chem. Int. Ed., 2017, 56, 7261-7265.

21. N. Deibl and R. Kempe, Angew. Chem. Int. Ed., 2017, 56, 16631666.

22. S. Gomez, J. A. Peters and T. Maschmeyer, Adv. Synth. Catal., 2002, 344, 1037-1057.

23. (a) B. Li, J.-B. Sortais and C. Darcel, RSC Adv., 2016, 6, 5760357625; (b) S. A. Lawrence, Amines: synthesis, properties and applications, Cambridge University Press, Cambridge, 2004.

24. (a) J. Zheng, S. Chevance, C. Darcel and J.-B. Sortais, Chem. Commun., 2013, 49, 10010-10012; (b) J. Zheng, S. Elangovan, D. A. Valyaev, R. Brousses, V. César, J.-B. Sortais, C. Darcel, N. Lugan and G. Lavigne, Adv. Synth. Catal., 2014, 356, 1093-1097; (c) D. A. Valyaev, D. Wei, S. Elangovan, M. Cavailles, V. Dorcet, J.-B. Sortais, C. Darcel and N. Lugan, Organometallics, 2016, 35, 4090-4098.

25. (a) H. Jaafar, H. Li, L. C. Misal Castro, J. Zheng, T. Roisnel, V. Dorcet, J.-B. Sortais and C. Darcel, Eur. J. Inorg. Chem., 2012, 3546-3550; (b) B. Li, J.-B. Sortais, C. Darcel and P. H. Dixneuf, ChemSusChem, 2012, 5, 396-399; (c) L. C. Misal Castro, J.-B. Sortais and C. Darcel, Chem. Commun., 2012, 48, 151-153; (d) L. P. Bheeter, M. Henrion, M. J. Chetcuti, C. Darcel, V. Ritleng and J.B. Sortais, Catal. Sci. Technol., 2013, 3, 3111-3116; (e) J. Zheng, T. Roisnel, C. Darcel and J. B. Sortais, ChemCatChem, 2013, 5, 28612864; (f) J. Zheng, C. Darcel and J.-B. Sortais, Chem. Commun., 2014, 50, 14229-14232.

26. D. Wei, A. Bruneau-Voisine, T. Chauvin, V. Dorcet, T. Roisnel, D. Valyaev, N. Lugan and J.-B. Sortais, Adv. Synth. Catal., 2018, 360, 676-681.

27. For benzaldehydes derivatives with anilines, the condensation may be carried out at r.t. in $1 \mathrm{~h}$, see table 2 , entry 4.

28. Ketimines are not reduced under these conditions, see Table $\mathrm{S} 5$ in SI.

29. M. Ishihara and H. Togo, Tetrahedron, 2007, 63, 1474-1480. 30. Under standard conditions, c.a. $10 \%$ of unsatured amine $\mathbf{d 4 0}$ was identified in the crude mixture. 